\title{
Health Benefits of the Low Emission Zone Introduction in Prague City Centre
}

\author{
V. Máca*, J. Melichar \\ Environment Center, Charles University in Prague, Czech Republic \\ *Corresponding author: vojtech.maca@czp.cuni.cz
}

DOI: $10.2478 / \mathrm{v} 10158-012-0030-3$

\begin{abstract}
This paper presents an assessment of the economic benefits of the possible introduction of a low emission zone in central Prague restricting the access of vehicles that do not meet specified emission limits. Two variants were considered: in the first scenario entry is banned for vehicles that do not meet the EURO 2 emission limit, and in the second scenario access restriction applies to vehicles that do not meet the EURO 3 emission limit. The spatial extent of the zone is designed to cover the wider city centre, while allowing unrestricted access on the boundary roads of the zone. Using the impact pathway approach based ExternE methodology, an estimation is made of the benefits from reduced emissions of air pollutants based on dispersion modelling of primary pollutants. The scope of assessment is limited to impacts on human health only; other effects caused by air pollution (as well as other externalities) are not covered. The results suggest that the introduction of a low emission zone would likely lead to a tiny reduction in negative impacts by $1 \%$ and $2.3 \%$, respectively, for a looser and stricter variant of the low emission zone. A policy lesson from this exercise is that if the introduction of a low emission zone in Prague is to be adopted, then thorough preparation and evaluation of alternative variants for the efficient fulfilment of the objective(s) sought should precede it.
\end{abstract}

KEY WORDS: Air pollution, low-emission zone, impact pathway approach, health benefit valuation.

\section{$1 \quad$ INTRODUCTION}

Prague, the capital of the Czech Republic, saw a massive growth in transport of about 300 percent (measured by vehicle-kilometres driven) between 1990 and 2011 (TSK-ÚDI, 2012). This traffic volume seriously compromises the quality of the environment for the inhabitants despite a significant improvement in vehicle emission performance and fuel quality, as well as the continuous development of the traffic network and traffic management. According to the latest report on air pollution, the 24-hour air quality limit for particulate matters (fraction $\mathrm{PM}_{10}$ ) was exceeded more than 35 times per year at 10 out of 17 air quality monitoring stations in the Prague agglomeration, with the majority of them categorized as relevant to traffic (Ostatnická et al., 2011).

This paper deals with a stylized assessment of the health benefits from the possible implementation of a low emission zone, i.e. designing areas with a ban on the entry of vehicles that do not meet specified emission limits. Only recently has the new Air Protection Act enabled local authorities to design low emission zones, inter alia, when air 
quality limits have been exceeded (see Art. 14 of Act no. 201/2012 Coll.). Recently, two studies from Germany explored the reduction of air pollution induced by low emission zones using time-series analysis. Wolff \& Perry (2011) find that the introduction of low emission zones leads to a reduction in $\mathrm{PM}_{10}$ levels by 7 to $9 \%$ in urban traffic areas, and Malina \& Fischer (2012) suggest that more stringent emission zones can reduce $\mathrm{PM}_{10}$ level even further.

Two variants of a low emission zone are considered in our study; in the first variant, the entry restriction applies to vehicles that do not meet the EURO 2 ("Variant 1") emission limit, and in the second variant the ban applies to vehicles that do not meet the EURO 3 ("Variant 2") emission limit. The spatial extent of the zone was designed to cover a wider area of the city centre that at the same time would allow for detoured traffic on the roads on the edge of the zone.

\section{METHODS}

The damage function approach is a generally recognized analytical approach to the valuation of environmental and transport externalities such as impacts on the environment, human health, buildings and infrastructure (Maibach et al., 2008). This approach, also called the impact-pathway approach (IPA) in the assessment of atmospheric emission impacts, has been developed since the 1990's in a number of projects supported by the European Commission, collectively called ExternE (Externalities of Energy). The impact-pathway approach was initially developed for the assessment of energy production (Bickel \& Friedrich, 2005), but in the late 1990's it was expanded to include the assessment of transportation (Friedrich \& Bickel, 2001).

IPA tracks individual pathways from pressure to state and impact, or more specifically pathways of pollutants from emission sources (i.e. change in traffic flow and/or its composition), to receptors (population, buildings, etc.) that bear the ensuing negative effects. The physical impacts on human health (mortality and morbidity), on crops, building materials and ecosystems are then translated into monetary terms. Goods and services are traded in the market using market prices, while non-market valuation methods are used for non-market goods. Such effects are "externalities" in economic terms, i.e. the unintended impacts on the utility (or production function) of the recipient of externality (e.g. an individual afflicted by respiratory problems induced by irritating pollutants). A corresponding measure of change in benefits (welfare) is the individual's willingness to pay (WTP), or willingness to accept compensation (WTA). The size of the changes in social welfare is usually understood as the sum of (changes of) individual benefits.

The approach taken in this paper is based on a detailed modelling of the atmospheric dispersion of primary pollutants (particulate matter, nitrogen oxides, sulphur dioxide, benzene, benzo(a)pyrene, and formaldehyde). A drawback of the Gaussian (plum) dispersion model used is that it does not allow for the accounting of secondary pollutants (such as tropospheric ozone), which would need to incorporate the chemical transformations taking place in the atmosphere into the model.

The input to the model is detailed data on individual emission sources, meteorological conditions, and data on reference points (coordinates, altitude, height above ground, character of the traffic flow). The data vary according to the type of emission sources that conventionally distinguish between area (e.g. intersections, parking lots) and line (roads) sources. The output of the model is pollutant concentration in reference points (short-term maximum concentrations and annual average concentrations). Depending on the density of the reference point network and the terrain complexity, an extrapolation to isolines 
and expression of impacts for concentration bands using geographic information systems is used. A formalized calculation of the physical impacts for each concentration band derived from the dispersion modelling then is

$$
\text { physical impact }=\text { concentration band } * \text { population at risk } * \text { risk group } * \text { CR function }
$$

where the concentration band is the annual (daily) concentration of the respective pollutant, population at risk is the age-determined proportion of the population relevant to the specific health impact, risk group is the proportion of the population (usually) with a higher sensitivity to a specific impact (e.g. asthmatics), CR function is the estimated relationship between exposure to a certain concentration band and the response in the form of a health impact (e.g. a new case of chronic bronchitis) or an increased risk of premature death. Physical impacts are then converted into monetary terms (external costs) using unit values which were determined by using valuation techniques for each impact type.

The concentration-response functions from the most recent update of the ExternE methodology (Bickel \& Friedrich, 2005) are used in the impact assessment. In the case of health impacts for population sub-groups at risk, the latest Czech Statistical Office data on the age structure of the overall Prague population were used. For valuation of the impacts (effects), default monetary values contained in the ExternE methodology are used.

\section{DATA}

Data on traffic flows, emissions and atmospheric dispersion were elaborated in a separate study reported in detail in Karel et al. (2011). The low emission zone was designed to include the wider city centre to the maximum extent bordering the completed parts of the inner ring road (cf. Figure 1). The acreage of the low emission zone is approximately $41 \mathrm{sq} . \mathrm{km}$.

The traffic volumes for 2009 were used in the calculations and the estimated changes in traffic after the introduction of the zone were determined by an expert estimate, not based on the traffic model (which would be the optimal approach) due to the limited scope of the study. The following assumptions (other than the known proportion of vehicles that do not meet a permitted emission class) were made:

- $20 \%$ of drivers will switch to a compliant vehicle within a short time i.e. they will keep driving into the zone, but the vehicle will meet the applicable emission limit;

- $30 \%$ of vehicles will no longer enter the zone - their drivers will use public transport or other means to address their needs in the city centre (internet, telephone, taxi, etc.);

- $50 \%$ of vehicles will bypass the zone - their destinations are outside the zone.

The respective zone entry restrictions reduce the traffic flows by the following amounts (per vehicle categories passenger cars / light duty vehicles / heavy duty vehicles / buses) $36 \%, 26 \%, 33 \%$ and $43 \%$ in variant 1 and $57 \%, 47 \%, 61 \%$ and $69 \%$ in variant 2 . Based on the assumption that a part of automobile traffic will move to alternate routes, the increase in emissions on the zone's borders was also taken into account. 


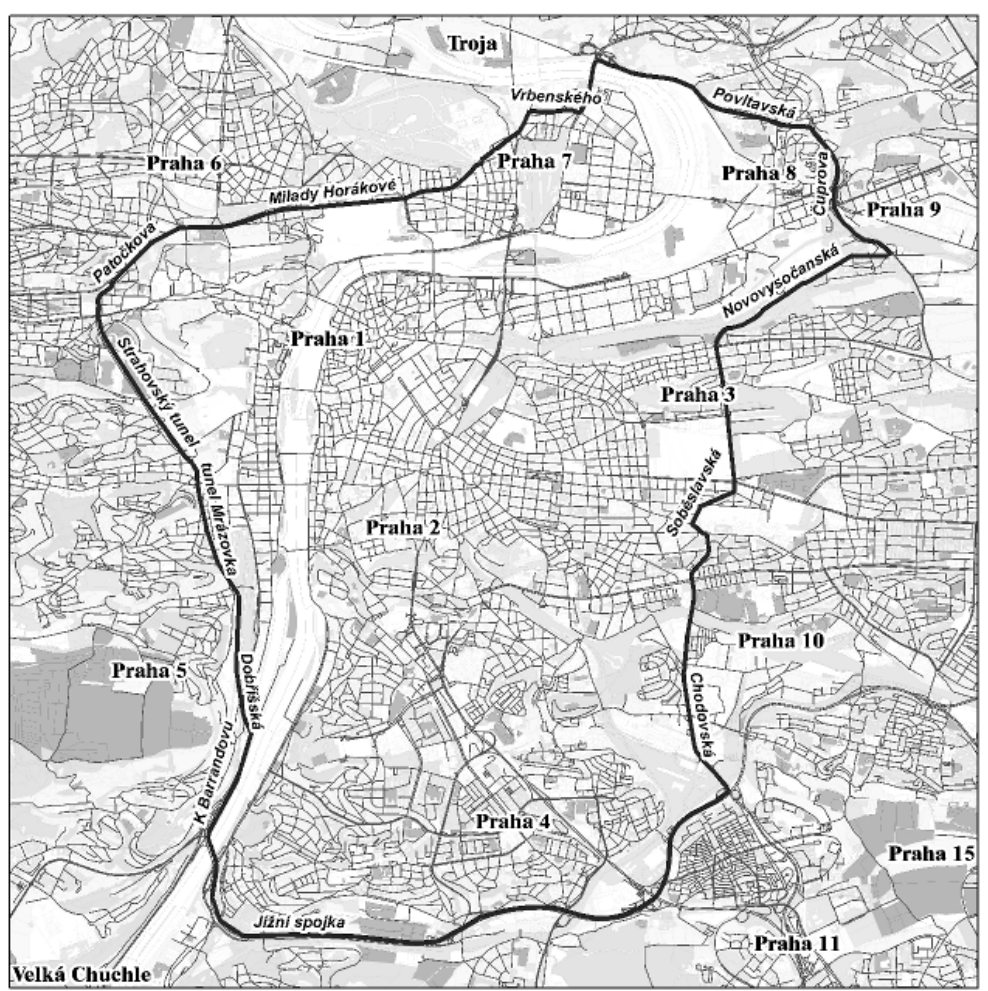

Figure 1: Map of designed low emission zone.

The emission inventory of $\mathrm{PM}_{10}$ and $\mathrm{PM}_{2.5}$ and other pollutants evaluated is summarized in the following table.

Table 1: Emissions of polluting substances inside and outside the zone (t.yr $\left.{ }^{-1}\right)$.

\begin{tabular}{|c|c|c|c|c|c|}
\hline & \multicolumn{3}{|c|}{ Absolute values } & \multicolumn{2}{|l|}{ Difference } \\
\hline & var0 & var1 & var2 & var1 - var0 & var2 - var0 \\
\hline $\mathbf{P M}_{10}$ & 843.2 & 906 & 781.9 & 62.8 & -61.3 \\
\hline inside the zone & 843.2 & 609.1 & 434.2 & -234.1 & -409 \\
\hline zone border & - & 296.9 & 347.7 & 296.9 & 347.7 \\
\hline $\mathbf{P M}_{2.5}$ & 256.6 & 265.6 & 233.2 & 9 & -23.4 \\
\hline inside the zone & 256.6 & 163.4 & 114.4 & -93.2 & -142.2 \\
\hline zone border & - & 102.2 & 118.8 & 102.2 & 118.8 \\
\hline $\mathrm{NO}_{2}$ & 1536.5 & 1411.3 & 1337.6 & -125.2 & -198.9 \\
\hline inside the zone & 1536.5 & 392.8 & 209.4 & -1143.7 & -1327.1 \\
\hline zone border & - & 1018.5 & 1128.2 & 1018.5 & 1128.2 \\
\hline $\mathrm{SO}_{2}$ & 9 & 8.3 & 7.7 & -0.7 & -1.3 \\
\hline inside the zone & 9 & 5.7 & 3.6 & -3.3 & -5.4 \\
\hline zone border & - & 2.6 & 4.1 & 2.6 & 4.1 \\
\hline benzene & 87.2 & 55.9 & 49.8 & -31.3 & -37.5 \\
\hline inside the zone & 87.2 & 17 & 9.2 & -70.3 & -78 \\
\hline zone border & - & 39 & 40.6 & 39 & 40.6 \\
\hline benzo(a)pyrene $\left(\mathrm{kg} \cdot \mathrm{yr}^{-1}\right)$ & 8907.8 & 8847.5 & 8795.5 & -60.3 & -112.3 \\
\hline inside the zone & 8907.8 & 5521.4 & 3645 & -3386.4 & -5262.8 \\
\hline zone border & - & 3326.1 & 5150.5 & 3326.1 & 5150.5 \\
\hline formaldehyde & 76.4 & 46.5 & 41 & -29.9 & -35.4 \\
\hline inside the zone & 76.4 & 16.5 & 8.8 & -59.9 & -67.6 \\
\hline zone border & - & 30 & 32.2 & 30 & 32.2 \\
\hline
\end{tabular}


Emissions of both fractions of particulate matters increase at the border zone; in Variant 1 they increase even more than the overall reduction inside the zone, while Variant 2 leads to an overall decrease in emissions of both fractions (the $\mathrm{PM}_{10}$ fraction decreases by about $7 \%$ and the $\mathrm{PM}_{2.5}$ fraction by approximately $9 \%$ ). $\mathrm{NO}_{2}$ emissions decrease in both variants, by about $8 \%$ in Variant 1 and by $13 \%$ in Variant 2. With respect to the emissions of other pollutants, a decrement occurs in both variants, and almost by a half in the case of benzene and formaldehyde in Variant 2.

\section{RESULTS}

\subsection{Baseline Impacts (Current Situation)}

The following table shows the quantified impacts on human health from exposure to emissions of particulates $\left(\mathrm{PM}_{2.5}\right.$ and $\left.\mathrm{PM}_{10}\right), \mathrm{SO}_{2}, \mathrm{NO}_{2}$, benzene, benzo(a)pyrene and formaldehyde inside the zone and at the zone's boundary (baseline scenario). The last two columns of the table show the impacts (external costs) estimated for the lower and upper limit of annual average concentrations of each respective pollutant.

Table 2: External costs of traffic-related air pollution in the baseline scenario (tsd. EUR 2000. $\mathbf{y r}^{-1}$ ).

\begin{tabular}{|l|l|r|r|}
\hline \multicolumn{1}{|c|}{ Pollutant } & \multicolumn{1}{|c|}{ Impact } & Lower estim. & Upper estim. \\
\hline $\mathrm{PM}_{2.5}$ & Life expectancy reduction & 228165 & 260989 \\
\hline $\mathrm{PM}_{2.5}$ & Minor restricted activity days & 12296 & 14064 \\
\hline $\mathrm{PM}_{2.5}$ & Work loss days & 35956 & 41128 \\
\hline $\mathrm{PM}_{2.5}$ & Restricted activity days & 17452 & 19721 \\
\hline $\mathrm{PM}_{10}$ & bronchodilator use (adults) & 48 & 59 \\
\hline $\mathrm{PM}_{10}$ & bronchodilator use (children) & 4 & 5 \\
\hline $\mathrm{PM}_{10}$ & Cardiac hospital admissions & 3015 & 128 \\
\hline $\mathrm{PM}_{10}$ & Increased mortality risk (infants) & 54505 & 3666 \\
\hline $\mathrm{PM}_{10}$ & New cases of chronic bronchitis & 18071 & 21978 \\
\hline $\mathrm{PM}_{10}$ & Lower respiratory symptoms (adults) & 11630 & 14144 \\
\hline $\mathrm{PM}_{10}$ & Lower respiratory symptoms (children) & 207 & 251 \\
\hline $\mathrm{PM}_{10}$ & Respiratory hospital admissions & 1030 & 1272 \\
\hline $\mathrm{SO}_{2}$ & Increased mortality risk & 13 & 16 \\
\hline $\mathrm{SO}_{2}$ & Respiratory hospital admissions & 2552 & 3063 \\
\hline $\mathrm{NO}_{2}$ & Increased mortality risk & 47 & 57 \\
\hline $\mathrm{NO}_{2}$ & Respiratory hospital admissions & 94 & 165 \\
\hline $\mathrm{Benzene}_{\mathrm{Benzo}(a) p y r e n e}$ & Cancer & 63 & 133 \\
\hline Formaldehyde & Cancer & 54 & 101 \\
\hline Total & & $\mathbf{3 8 5 3 2 8}$ & $\mathbf{4 4 7 2 5 6}$ \\
\hline
\end{tabular}

Human health impacts from the current level of traffic-related emissions inside and around the zone are estimated in the range of EUR 385-447 million per year. Approximately $3 / 4$ of this sum is attributable to the effects associated with exposure to fine dust particles $(2.5 \mu \mathrm{m}$ fraction); most of the remaining damage is associated with the impacts of coarse particulates (10 $\mu \mathrm{m}$ fraction), while the share of impacts associated with the other pollutants $\left(\mathrm{SO}_{2}, \mathrm{NO}_{2}\right.$, benzene, benzo(a)pyrene and formaldehyde) does not exceed $1 \%$ of the total sum. 


\subsection{Change in Impacts from the Introduction of a Low Emission Zone}

Table 3 shows quantified potential benefits (negative values) and additional damage (positive values), respectively, from the introduction of a low emission zone according to the variant under consideration. In economic terms, for Variant 1 the total effects range from benefits of about EUR 11.5 million to additional damage of about EUR 6.2 million or, in percentage terms, from a $3 \%$ reduction to a $1.4 \%$ increase in the external costs vis-à-vis the baseline situation. In Variant 2, the estimated effects range from benefits of EUR 18.8 million to additional damage of about EUR 2.2 million or, in percentage terms, from a 5\% reduction to a $0.5 \%$ increase compared to the baseline situation.

Table 3: Change in external effects from the introduction of a low emission zone (tsd. EUR ${ }_{2000} . \mathrm{yr}^{-1}$ ).

\begin{tabular}{|c|c|c|c|c|c|}
\hline \multirow[b]{2}{*}{ Pollutant } & \multirow[b]{2}{*}{ Impact } & \multicolumn{2}{|c|}{ var1 - var0 } & \multicolumn{2}{|c|}{ var2 - var0 } \\
\hline & & $\begin{array}{l}\text { Lower } \\
\text { estim. }\end{array}$ & $\begin{array}{l}\text { Upper } \\
\text { estim. }\end{array}$ & $\begin{array}{l}\text { Lower } \\
\text { estim. }\end{array}$ & $\begin{array}{l}\text { Upper } \\
\text { estim. }\end{array}$ \\
\hline $\mathrm{PM}_{2.5}$ & Life expectancy reduction & -6017 & 3753 & -10778 & 2275 \\
\hline $\mathrm{PM}_{2.5}$ & Minor restricted activity days & -505 & 315 & -581 & 123 \\
\hline $\mathrm{PM}_{2.5}$ & Work loss days & -1460 & 911 & -1699 & 359 \\
\hline $\mathrm{PM}_{2.5}$ & Restricted activity days & -730 & 495 & -793 & 238 \\
\hline $\mathrm{PM}_{10}$ & bronchodilator use (adults) & -2 & 0 & -3 & 0 \\
\hline $\mathrm{PM}_{10}$ & bronchodilator use (children) & 0 & 0 & 0 & 0 \\
\hline $\mathrm{PM}_{10}$ & Cardiac hospital admissions & -4 & 1 & -7 & -1 \\
\hline $\mathrm{PM}_{10}$ & Increased mortality risk (infants) & -98 & 25 & -171 & -28 \\
\hline $\mathrm{PM}_{10}$ & New cases of chronic bronchitis & -1767 & 458 & -3088 & -502 \\
\hline $\mathrm{PM}_{10}$ & Lower respiratory symptoms (adults) & -586 & 152 & -1024 & -167 \\
\hline $\mathrm{PM}_{10}$ & $\begin{array}{l}\text { Lower respiratory symptoms } \\
\text { (children) }\end{array}$ & -377 & 98 & -659 & -107 \\
\hline $\mathrm{PM}_{10}$ & Respiratory hospital admissions & -7 & 2 & -12 & -2 \\
\hline $\mathrm{SO}_{2}$ & Increased mortality risk & -5 & 3 & -6 & 2 \\
\hline $\mathrm{SO}_{2}$ & Respiratory hospital admissions & 0 & 0 & 0 & 0 \\
\hline $\mathrm{NO}_{2}$ & Increased mortality risk & -254 & -7 & -298 & -26 \\
\hline $\mathrm{NO}_{2}$ & Respiratory hospital admissions & -5 & 0 & -6 & 0 \\
\hline Benzen & Cancer & -49 & 1 & -55 & -2 \\
\hline Benzo(a)pyren & Cancer & -38 & 14 & -40 & 13 \\
\hline Formaldehyd & Cancer & -53 & 3 & -57 & 1 \\
\hline \multicolumn{2}{|l|}{ Total } & -11956 & 6224 & -19277 & 2174 \\
\hline \multicolumn{2}{|c|}{ Percentage change from baseline situation } & $-3.1 \%$ & $1.4 \%$ & $-5.0 \%$ & $0.5 \%$ \\
\hline
\end{tabular}

Notes: negative values represent a potential benefit from the zone compared to the baseline.

Besides the simple summing of the impacts of changes, one can further explore what the distribution of benefits and additional burden in the population of the territory under consideration are. The following figure illustrates the distribution of benefits and additional damage from the implementation of low-emission zones in Variant 1. The population for whom there is a change in the concentration of particulates from the introduction of a low emission zone is plotted on the horizontal axis, while the impact change in monetary term is plotted on the vertical axis. Positive benefits, i.e. a reduction of $\mathrm{PM}_{10}$, will benefit about 247,000 residents in the territory, while the additional burden will be borne by approximately 116 thousand residents. For $\mathrm{PM}_{2.5}$, the benefits will be enjoyed by some 127,000 citizens, while about 40 thousand citizens will bear the additional burden 
from a concentration increase. Both graphs show that the distribution of the benefits is relatively steep in comparison with the additional damage.
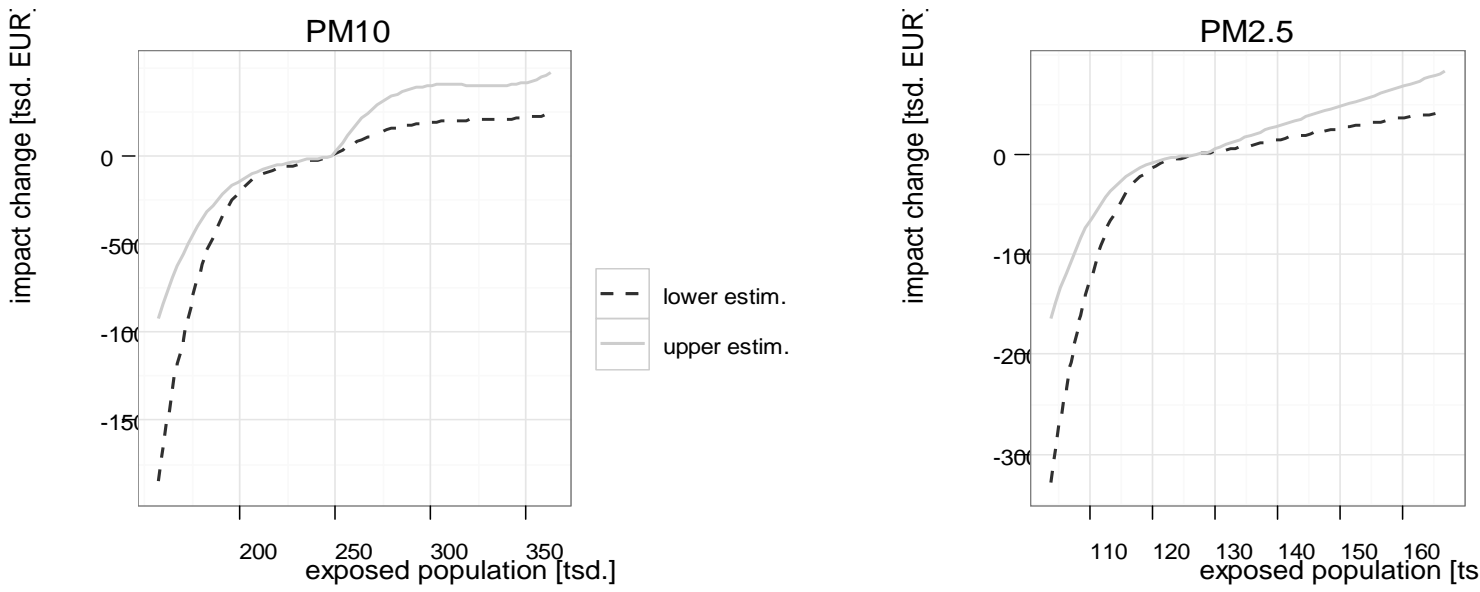

Figure 2: Distribution of benefits or additional damage in the affected population in Variant 1.

The cumulative distribution of effects, benefits or additional damage in Variant 2 for $\mathrm{PM}_{10}$ and $\mathrm{PM}_{2.5}$ is shown in the next figure. Reduced concentrations of $\mathrm{PM}_{10}$ will benefit about 274,000 residents in the territory in this variant; the additional burden will be borne by approximately 107,000 citizens. Similarly, the positive benefits of a $\mathrm{PM}_{2.5}$ concentration reduction will be enjoyed by 222,000 citizens, while in contrast some 44,000 citizens will suffer from increased air pollution. The distribution of benefits and additional damage from the other pollutants under consideration could be expressed in the same way, but the overall effect is negligible compared to the impact of particulates.
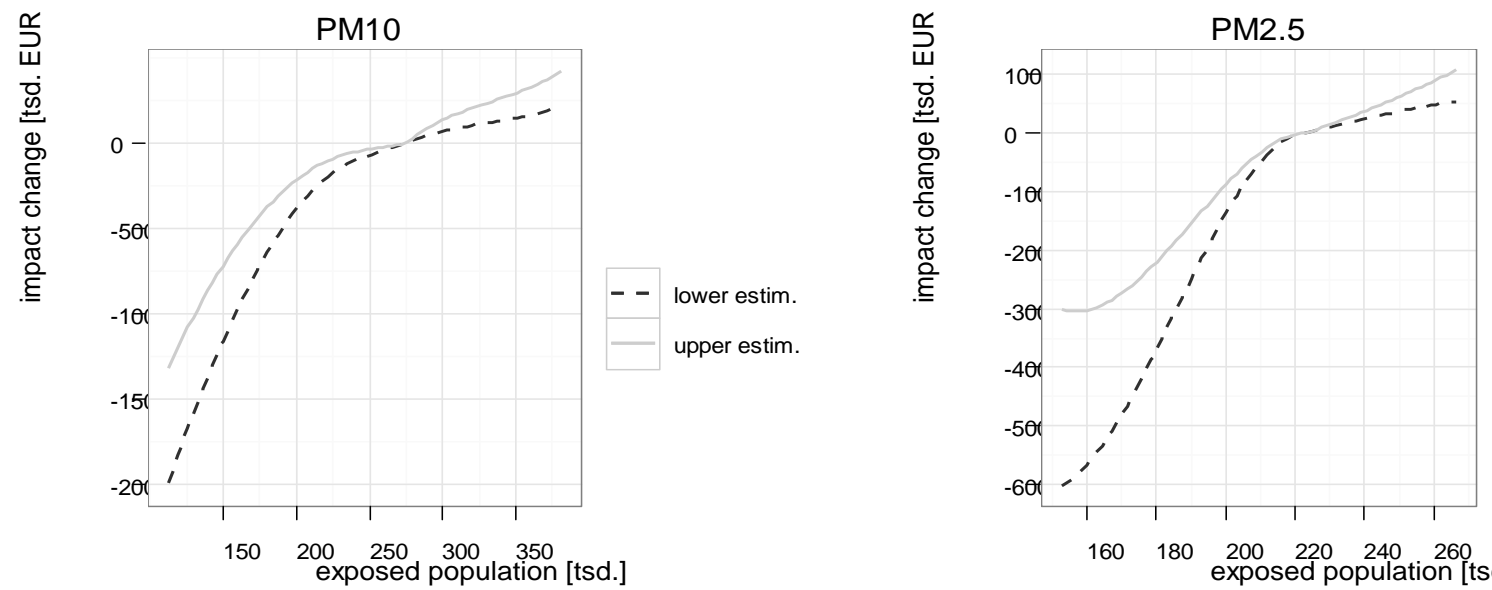

Figure 3: Distribution of benefits or additional damage in the affected population in Variant 2.

\section{CONCLUSIONS}

The assessment of the benefits from the introduction of a low emission zone in the Prague city centre presented here shows a relatively marginal reduction in external costs from traffic-related air pollution. The overall benefit amounts to a several per cent reduction, albeit with a relatively differentiated distribution in the population. While there is a modest pollution reduction inside the zone, the opposite situation occurs on the zone's boundary, where an increase in air pollution concentration is caused by increased traffic bypassing the zone. 
Although it is a rather approximate model calculation, our assessment clearly shows the need for thorough preparation prior to any planned introduction of a low emission zone in Prague and in-depth evaluation of the alternatives - meaning not only a focus on entry bans on vehicle emission classes, but also on how to design zone borders because a substantial improvement in air quality for residents will only be achieved when an alternative route used in increasing numbers by vehicles failing to comply with emission zone entry limits is located outside densely populated residential areas.

Although the primary goal of low emission zones is to improve local air quality it is also necessary to take into account other induced effects. While a decrease in the number of vehicles in the city centre is a welcome effect, the impacts in terms of accessibility might be ambiguous while less cars means reduced congestion inside the zone it may on the other hand hamper access to locations inside the zone (but this will depend on the changes in public transport and modal choice options). Some related effects including noise and crowded parking reduction can be expected inside the zone but these will likely worsen on its boundary. In addition, more indirect effects such as an increased demand for new (or compliant) vehicles may be expected in the short term with a possible reduction in demand in the longer term.

\section{ACKNOWLEDGEMENTS}

The research reported in this article was supported by Technological Agency of the Czech Republic, project no. TA02021165.

\section{REFERENCES}

Bickel, P., Friedrich, R., 2005. ExternE: Externalities of Energy. Methodology 2005 Update. Luxembourg: Office for Official Publications of the European Communities. ISBN 92-79-00423-9.

Friedrich, R., Bickel, P., 2001. Environmental external costs of transport. Berlin: SpringerVerlag. ISBN 978-3-540-42223-5.

Karel, J. et al., 2011. Zavedení nízkoemisní zóny na komunikační síti v Praze - modelové hodnocení kvality ovzduší. Studie pro COŽP UK. Praha: ATEM - Ateliér ekologických modelů, s.r.o. (in Czech)

Maibach, M., Schreyer, C., Sutter, D., van Essen, H., P., Boon, B. H., Smokers, R. et al., 2008. Handbook on Estimation of External Cost in the Transport Sector. Delft: CE Delft.

Malina, Ch., Fischer, F., 2012. The impact of low emission zones on PM10 levels in urban areas in Germany (Working Paper No. 58). Muenster: Institute of Transport Economics, University of Muenster.

Ostatnická, J. et al., 2011. Znečištění ovzduši na územi České republiky v roce 2010. Praha: Český hydrometeorologický ústav. (in Czech)

TSK-ÚDI, 2012. Ročenka dopravy Praha 2011. Praha: Technická správa komunikací hl. m. Prahy. (in Czech)

Wolff, H., Perry, L., 2011. Keep your clunker in the suburb. Low emission zones and adoption of green vehicles, working paper [online]. Washington: University of Washington. 50 p. [cited 2013-02-09]. Retrieved from: http://faculty.washington.edu/hgwolff/LEZ.pdf 